\title{
GESTÃO DE PROJETOS SOCIAIS: UMA ANÁLISE DO MODELO DE GERENCIAMENTO ADOTADO POR UMA SECRETARIA MUNICIPAL DE DIANÓPOLIS/TO, A PARTIR DO GUIA PMBOK
}

Social Project Management: An analysis of the management model adopted by a Municipal Secretariat in Dianópolis / TO, based on the PMBOK guide Gestión de proyectos sociales: un análisis del modelo de gestión adoptado por una Secretaría Municipal en Dianópolis / TO, basado en la guía PMBOK

\author{
Edna Primo da Silva ${ }^{* 1}$, Josivaldo Alves da Silva ${ }^{2}$ \\ ${ }^{\text {I}}$ Bacharel em Administração pela Universidade Estadual do Tocantins Unitins, Câmpus Dianópolis. \\ *Correspondência: Universidade Estadual do Tocantins-Unitins, Praça Aurélio Antônio Araújo n 2-Centro, \\ Dianópolis, Tocantins, CEP: 77-300-000,ednacvc@gmail.com. \\ ${ }^{2}$ Doutorando e Mestre em Desenvolvimento Regional pela Universidade Federal do Tocantins-UFT; Especialista Lato Senso \\ em Docência do Ensino Superior; MBA em Planejamento e Gestão Empresarial; Graduado em Administração; Professor 40 \\ horas Universidade do Tocantins-Unitins Câmpus Dianópolis; Pesquisador orientador de iniciação científica PIBIC/PIVIC. \\ *Correspondência: Universidade Estadual do Tocantins-Unitins, Praça Aurélio Antônio Araújo n 2-Centro, \\ Dianópolis, Tocantins, CEP: 77-300-000, josivaldoadm@ yahoo.com.br.
}

Artigo recebido em 22/03/2020 aprovado em 30/10/2020 publicado em 30/12/2020.

\section{RESUMO}

O presente artigo tem como objetivo analisar o modelo de gerenciamento de Projetos Sociais estabelecidos pela Prefeitura de Dianópolis/TO, executados pela Secretaria de Esportes e Juventude no período de $1^{\mathrm{o}}$ de janeiro de 2017 a 20 de setembro de 2019, a partir do guia PMBOK. Os tipos de pesquisas utilizadas na investigação foram: exploratória, bibliográfica, documental, descritiva e explicativa através de um estudo de caso. Quanto à metodologia empregada na coleta, análise e interpretação dos dados foi a qualitativa. O estudo de caso foi executado no período de 22 de agosto a 20 de setembro de 2019. O instrumento de coleta de dados foi; um questionário semi-estruturado com dez questões abertas, aplicado presencialmente pelos pesquisadores ao Secretário de Esportes e juventude, principal responsável pelo gerenciamento dos projetos da pasta. Através da pesquisa foi possível observar dois pontos fundamentais: a Secretaria de Esporte e Juventude, não utiliza um guia de gerenciamento de projetos para padronizar os processos, estabelecer diretrizes claras de gestão, e não dispõe de profissionais capacitados para atuar no gerenciamento dos respectivos projetos conforme estabelece as normas.

Palavras-chave: Gestão de projetos; projetos sociais; Dianópolis.

\section{ABSTRACT}

This article aims to analyze the management model of Social Projects established by the City of Dianópolis / TO, executed by the Sports and Youth Secretariat from January 1, 2017 to September 20, 2019, using the PMBOK guide. The types of research used in the investigation were: exploratory, bibliographic, documentary, descriptive and explanatory through a case study. As for the methodology used in the collection, analysis and interpretation of the data, it was qualitative. The case study was carried out from August 22 to September 20, 2019. The data collection instrument was; a semi-structured questionnaire with ten open questions, applied in person by the researchers to the Secretary of Sports and Youth, who is primarily responsible for managing the portfolio's projects. Through the research it was possible to observe two fundamental points: the Secretariat of Sport and Youth, does not use a project management guide to standardize the processes, establish clear management guidelines, and does not have trained professionals to act in the management of the respective projects as sets the standards.

Keywords: Project Management; social projects; Dianópolis. 


\section{RESUMEN}

Este artículo tiene como objetivo analizar el modelo de gestión de Proyectos Sociales establecido por la Ciudad de Dianópolis / TO, ejecutado por la Secretaría de Deportes y Juventud del 1 de enero de 2017 al 20 de septiembre de 2019, utilizando la guía PMBOK. Los tipos de investigación utilizados en la investigación fueron: exploratorio, bibliográfico, documental, descriptivo y explicativo a través de un estudio de caso. En cuanto a la metodología utilizada en la recopilación, análisis e interpretación de los datos, fue cualitativa. El estudio de caso se realizó del 22 de agosto al 20 de septiembre de 2019. El instrumento de recolección de datos fue; un cuestionario semiestructurado con diez preguntas abiertas, aplicado personalmente por los investigadores al Secretario de Deportes y Juventud, quien es el principal responsable de administrar los proyectos de la cartera. A través de la investigación, fue posible observar dos puntos fundamentales: la Secretaría de Deportes y Juventud, no utiliza una guía de gestión de proyectos para estandarizar los procesos, establece pautas claras de gestión y no cuenta con profesionales capacitados para actuar en la gestión de los proyectos respectivos establece los estándares.

Descriptores: Gestión de proyectos; proyectos sociales; Dianópolis.

\section{INTRODUÇÃO}

A decisão dos formuladores de políticas públicas de implementar programa social sempre parte do pressuposto de que a intervenção terá impacto positivo sobre um conjunto de resultados de interesse coletivo e deve proporcionar benefícios para ao menos uma parcela da sociedade. A execução desses programas se dá por meios do estabelecimento de projetos de cunho sociais, sendo um esforço temporário empreendido pelos entes públicos como instrumentos de gestão com a finalidade de reduzir as desigualdades sociais.

Destarte, o conceito de projeto pode ser considerado como um tipo de planejamento, utilizado como parte de um programa normalmente caracterizase por ser mais limitados no tempo. Por outro lado, o projeto social é caracterizado como um conjunto de ações planejadas e estruturadas em objetivos, metas e atividades com o propósito de resolver um problema público com uma quantidade limitada de recursos humanos, materiais e financeiros em um período de tempo pré-estabelecido.

Além disso, as definições dos conceitos de gerenciamento de projeto estão sustentadas nos fundamentos teóricos da administração pública como processo de tomadas decisões, delineados pelos elementos de planejamento, organização, liderança, execução e controle (MAXIMIANO, 2012). Dessa forma, a complexidade de aplicação dos fundamentos da administração pública gerencial, voltada para as pretensões dos cidadãos, no qual se orienta para a obtenção de resultados, principalmente nos municípios, torna-se fundamental a utilização do guia PMI; PMBOK, como um modelo padrão para o gerenciamento de projetos, assim como a transformação do escopo em ferramentas e técnicas gerenciais com intuito de atender aos seus requisitos podem-se tornar em um fator preponderante para aumentar a eficiência e a eficácia dos serviços públicos.

Nesse sentido, a implementação de um modelo de gerenciamento de projeto obedecendo aos padrões e guias internacionais, poderá contribuir para a institucionalização de boas práticas na gestão pública dos municípios. A utilização de boas práticas de gerenciamento de projeto pode proporcionar maiores chances na capacidade de atender melhor essas pessoas, visando ser um facilitador e um instrumento de gestão e de governança, pois, é de sua natureza que as fases do projeto sejam documentadas.

No caso da Prefeitura de Dianópolis/TO, consta na sua estrutura organizacional, importantes pastas que por natureza tem um papel fundamental na implementação de projetos sociais para serem utilizados como instrumento de gestão de políticas públicas que possam contribuir para a inclusão de pessoas no contexto social, delimitou-se como objeto 
de estudo a Secretaria Municipal de Esportes e Juventude.

Nesse aspecto, dada a importância do projeto social quando bem gerenciado seguirá uma programação para o seu devido desenvolvimento, deve-se obedecer às fases de iniciação, planejamento, execução, controle e encerramento, aventa-se a hipótese de que a Secretaria de Esportes e Juventude de Dianópolis, adota um guia padrão no gerenciamento de seus projetos.

Cabe ressaltar que, alguns trabalhos têm sido desenvolvidos objetivando a orientação para aplicação de ferramentas e técnicas de gerenciamento de projetos, (LEWIS; COUTO, 2000); (GAUDEOSO, 2014) e (PRIETA; MÉXAS, 2016); porém, nenhum trabalho foi feito visando à análise da modelo de gerenciamento de Projetos Sociais estabelecidos pela Prefeitura de Dianópolis/TO. Posto isto, o objetivo deste artigo é analisar o modelo de gerenciamento de Projetos Sociais estabelecidos pela Prefeitura de Dianópolis/TO e executados pela Secretaria de Esportes e Juventude no período de $1^{\mathrm{o}}$ de janeiro de 2017 a 20 de setembro de 2019, a partir do guia PMBOK. Essa escolha foi motivada pela necessidade de se entender como os gestores da Secretaria de Esportes e Juventude de Dianópolis/TO, planejam e gerenciam os projetos sociais? Quais são os modelos de gerenciamento adotados?

Este artigo está estruturado na seguinte ordem: na primeira apresenta os conceitos e definições gestão de projeto e gerenciamento de projetos a partir do Guia PMBOK. Na segunda, apresentam-se, os pressupostos teóricos de projetos sociais, um breve histórico dos projetos sociais no Brasil e no Tocantins. A terceira apresenta-se a metodologia, resultados e análise dos resultados. Finalizando com as conclusões.

\section{GESTÃO DE PROJETOS}

Inicialmente, Vargas (2005) apresenta a definição conceitual de projeto como um conjunto de ações que abrangem todos os níveis da organização, envolvendo pessoas, incluindo os recursos materiais e tecnológicos por meio da realização de um evento não repetitivo com início, meio e fim, com a finalidade de alcançar um objetivo claro e definido. Além do mais, projeto é um esforço temporário que tem início e fim definidos para a criação de um produto ou serviço único. Esses projetos podem gerar impactos sociais, econômicos ou ambientais com um período de tempo mais extenso (PMBOK, 2014).

Certamente, na prática, um projeto é um esforço temporário empreendido para criar um produto, serviço ou resultado exclusivo. A sua natureza temporária implica o início e o término com prazos definidos. O término é determinado quando os objetivos tiverem sido atingidos ou quando se concluir que esses objetivos não poderão ser alcançados e o projeto for encerrado, ou quando o mesmo não for mais necessário (PMBOK, 2018). Desse modo, o tempo de duração do projeto está condicionado à resolução do problema que viabilizou e justificou a sua implementação.

Em outras palavras, Menezes (2009) afirma que um projeto é dinâmico e em alguns casos são necessários antecipar suas atividades para que ocorra no prazo e com o orçamento previsto, deve ser definido de forma clara com as datas de início, meio e fim definidas com a maior clareza possível.

De tal forma, a gestão de projetos é um tema que vem ganhando espaço nas organizações públicas, seja da esfera federal, estadual ou municipal. Para e execução desses projetos de forma adequada é necessário a aplicação de técnicas e estratégias gerenciais por meio de um esforço empreendido de forma temporário e exclusivo para criar um produto ou serviço, mas para isso é primordial que os gestores envolvidos disponham de habilidades e competências 
essências para elaboração de um planejamento tático e operacional para atingir os objetivos nos prazos determinados com a otimização dos recursos humanos, financeiros, materiais e tecnológicos disponíveis.

Nesse sentido, Meneses (2009) enfatiza que a administração de projeto ajuda as organizações que querem uma posição melhor frente aos desafios, auxiliando a avançar nas possíveis vantagens competitivas que pode estar desenvolvendo. Assim sendo, a implementação de políticas públicas por meio de projetos para resolver problemas públicoscontingênciais pode contribuir efetivamente para a eficiência na administração pública e atender as necessidades dos cidadãos que serão beneficiados com o produto do projeto.

Conforme as afirmações de Keeling (2002), gestão em formas de projetos vêm acontecendo há muito tempo, porém, vem se modernizado, alcançando patamares de complexidade e popularidade. Inicialmente estavam relacionados ao poder, religião e grandes monumentos. Uma vez que, atualmente a temática da gestão de projetos está relacionada à redução de custos como estratégia para o alcance da eficiência em todos os processos para atingir os resultados esperados.

Além do mais, o gerenciamento de um projeto ocorre de forma simultânea, abrange todos os indivíduos que trabalham no mesmo, desde a concepção até a sua conclusão, de forma que estejam informados e possam participar em questão que lhes digam respeito (LEWIS; COUTO, 2000). Assim sendo, para o projeto alcançar os resultados esperados no seu escopo é necessária a efetiva participação das pessoas interessadas, desde o planejamento até a elaboração do plano de execução.

Assim como, as principais características da gestão de projetos podem se diferenciar em relação à outra, são: a simplicidade de propósito, clareza de propósito e escopo, controle, facilidade de medição e flexibilidade, tudo isso conduz a motivação e moral da equipe envolvida, sensibilidade ao estilo de administração e liderança, útil ao desenvolvimento individual, favorece a discrição e a segurança, mobilidade e facilidade de distribuição (KEELING, 2002).

De maneira semelhante, o gerenciamento de projetos é um conjunto de ferramentas e técnicas que envolvem um conjunto de habilidades, de conhecimentos e capacidades individuais, voltado para o controle de eventos exclusivos, com tempo, custo e qualidade bem definidos (VARGAS, 2005). Contudo, a aplicação desses fundamentos gerenciais exigidos no escopo do projeto, é necessária a formação de uma equipe com formação relacionada à finalidade do mesmo e a capacitação das pessoas envolvidas na execução das ações pertinentes.

Em outros termos, o gerenciamento de projeto engloba a aplicação de conhecimentos, habilidades e técnicas capazes de lançar atividades que se faz cumprir com as exigências estabelecidas para o alcance dos resultados esperados, trata-se de uma competência estratégica para as organizações fazendo a junção dos resultados do projeto com os objetivos do negócio (OLIVEIRA; CHIARI, 2015). Assim, a aplicação desses fundamentos e técnicas de forma adequada, facilita a execução das metas, atividades e tarefas pertinentes, favorecendo a redução de custos, tempo e o alcance da qualidade esperada.

Em síntese, a partir dos pressupostos conceituais apresentados, é possível observar que, na prática, a gestão de projetos, trata-se da aplicação de um conjunto de ferramentas gerenciais delimitadas em um caso específico e voltadas para o planejamento e execução das ações que sustentam as metas e objetivos previstos para resolver o problema que justifica a implementação do projeto. Posto isto, na 
seção seguinte serão apresentados os elementos de gerenciamento de projetos a partir do guia PMBOK.

\section{Gerenciamento de projetos a partir do guia PMBOK}

O guia PMBOK, foi produzido pelo Instituto de Gerenciamento de Projetos (PMI) fundado em 1969, na Pensilvânia, nos Estados Unidos, a primeira edição do guia foi publicada em 1996, passando a ser responsável por gerenciar e atualizar as melhores práticas utilizadas por gerentes de projetos em todo mundo, e a segunda em 2000, a terceira em 2004, a quarta em 2008, a quinta em 2013, em 2018, a sexta edição foi colocada em circulação. Essa mais recente edição trouxe como novidade, a descrição do papel e as competências do gerente de projetos, incluindo o triângulo dos talentos que engloba as habilidades técnicas, habilidades estratégicas, dando maior ênfase aos aspectos de negócio, habilidades de liderança e gerenciamento de benefícios (PMBOK, 2018).

De tal forma, o Guia PMBOK, é um conjunto de conhecimentos técnicas que orienta os gestores a boas práticas e podem ser transformadas em ferramentas de gerenciamento de projetos. Também fornece um vocabulário específico para se discutir, escrever e aplicar o gerenciamento de projetos entre os profissionais envolvidos. O guia é baseado em várias áreas e processos gerenciais que organiza e sistematiza o trabalho a ser realizado durante o projeto através do processamento das atividades executadas com a utilização dos insumos necessários para se chegar ao produto final, seguindo uma lógica definida para a condução do trabalho, realizada através de entradas e saídas.

Nesse sentido, processo é um conjunto de atividades sequenciais inter-relacionadas que apresentam uma relação lógica entre si com uma ou mais tipos de entradas, as quais criam saídas de um produto acabado ou serviço concluído (LACOMBE, 2004).

Dessa forma, Guia PMBOK estabelece que o gerenciamento de projeto seja executado por meio da aplicação e integração de processos que são divididos em cinco grupos, a saber: iniciação; planejamento; execução; monitoramento-controle e encerramento (PMBOK, 2018).

A iniciação trata-se das atividades iniciais do projeto, que surge através da identificação da necessidade de resolução do problema é identificada mediante aos estudos preliminares e os primeiros documentos são confeccionados (VARGAS, 2018). Nessa fase, apresentam-se os processos necessários para a definição de um novo projeto através da obtenção de uma autorização para iniciar as atividades e a identificação das partes interessadas. Neste primeiro momento deve-se identificar a real necessidade do projeto para a organização, a viabilidade do mesmo através da elaboração do 83 escopo preliminar e definição dos objetivos estratégicos que deverão atendidos.

O planejamento é a fase mais importante, pois, o sucesso do projeto está diretamente relacionado à qualidade do planejamento realizado, devem-se descrever os processos necessários para definir refinar os objetivos e definir a linha de ação necessária para alcançar os objetivos para os quais o projeto foi criado (VARGAS, 2018). Nessa fase o gerente do projeto deve: Planejar o gerenciamento do escopo; coletar os requisitos; definir o escopo; planejar o gerenciamento do cronograma; definir as atividades; sequenciar as atividades; estimar a duração das atividades; desenvolver o cronograma; planejar o gerenciamento dos custos; estimar os custos; determinar o orçamento; planejar o gerenciamento da qualidade; planejar o gerenciamento dos recursos e estimar os recursos das atividades (PMBOK, 2018). 
$\mathrm{Na}$ execução apresentam-se, os processos necessários para executar o trabalho definido no Plano de Gerenciamento do Projeto, a fim de satisfazer as especificações do projeto visando a materialização daquilo que foi planejado (VARGAS, 2018). Nessa fase, o gerente deve-se adquirir os recursos; desenvolver a equipe e gerenciar a qualidade (PMBOK, 2018).

$\mathrm{Na}$ fase de monitoramento e controle apresentam-se os processos para analisar, acompanhar, e controlar o progresso e desempenho do projeto, identificando quaisquer áreas nas quais pode ser necessário realizar alterações no plano, iniciando assim, as mudanças necessárias (OLIVEIRA; CHIARI, 2015). Nessa fase o gerente do projeto deve: validar o escopo; controlar o escopo; monitorar o engajamento das partes interessadas; controlar o cronograma; controlar as aquisições; controlar e monitorar o trabalho do projeto; controlar os custos; monitorar os riscos; realizar o controle integrado de mudanças; controlar a qualidade; monitorar as comunicações; controlar os recursos (PMBOK, 2018).

Logo, o encerramento do projeto é ultima etapa das fases que se encontram os processos necessários para finalizar todas as atividades de todos os grupos de processos, objetivando encerrar, formalmente. A última fase que os documentos do projeto são finalizados. Nessa fase, os erros ocorridos no projeto são discutidos e analisados durante esse processo, visando aperfeiçoar em novos projetos, evitando que tais falhas sejam cometidas novamente (VARGAS, 2018).

Dessa forma, as fases também são denominadas de ciclo de vida do projeto. Cada projeto tem características diferentes um do outro. O que se assemelha são as fases do ciclo de vida de um projeto. Assim, o ciclo de vida de um projeto são as fases pela qual o projeto passa desde a sua concepção até a sua conclusão. Na medida em que o projeto passa por essas fases, mais recursos e tempos despendidos aumentarão, e consequentemente, o prazo e recursos restantes diminuíram (KEELING, 2002).

De tal modo, o Guia PMBOK estabelece que os processos de gestão dos projetos devem ser organizados e integrados em nove etapas a saber: 1) Gerenciamento da Integração; 2) Gerenciamento do Escopo; 3) Gerenciamento do Tempo; 4) Gerenciamento dos custos; 5) Gerenciamento da Qualidade; 6) Gerenciamento dos Recursos Humanos;

7) Gerenciamento das Comunicações; 8) Gerenciamento dos Riscos; 9) Gerenciamento das Aquisições; 10) Gerenciamento das Partes interessadas.

O Gerenciamento da Integração assegura que os diversos elementos do projeto sejam adequadamente coordenados. Envolve a tomada de decisão ligada diretamente aos objetivos do projeto e execução do plano do projeto, é composto pelos processos de desenvolvimento do termo de abertura do projeto, desenvolve o plano de gerenciamento, orienta e gerencia a execução das atividades do projeto, monitora e controla o trabalho, realiza o controle integrado de mudanças, até o encerramento do projeto (PMI, 2008).

Assim, o gerenciamento da integração deve ser implementado por meio da criação de um sistema para integrar todos os elementos do projeto que serão adequadamente coordenados para a busca de soluções dos problemas com a participação de toda equipe envolvida, para o alcance de melhores resultados das ações com a utilização de ferramentas para o controle geral das mudanças.

De foto, no gerenciamento do escopo descrevem-se os processos necessários para assegurar que o projeto contemple os requisitos acordados, e nada mais que os requisitos acordados, o que garantirá o sucesso do projeto. Trata-se dos processos de coletar os requisitos, definir, criar, verificar e controlar o 
escopo (DINSMORE; CAVALIERI, 2003; PMBOK, 2008). Assim sendo, na Gestão de escopo deve-se descrever como clareza como serão mapeados todos os processos necessários na execução do projeto criando um sistema padronizado que contemple todo o trabalho requerido.

No Gerenciamento do tempo apresentam-se os processos necessários para assegurar que o projeto termine dentro do prazo previsto. Ele é composto pelos processos de definir as atividades, sequenciar as atividades, estimar a duração das atividades, estimar os recursos das atividades, desenvolver e controlar cronograma (DINSMORE; CAVALIERI 2003; PMBOK 2004). Nessa fase, deve-se estabelecer delineamento detalhado do cronograma de execução com todas as ações previstas, com datas e locais préestabelecidos para a realização dos eventos planejados.

O gerenciamento de custos são fatores que objetivo a racionalização dos empregados nos Recursos Humanos e Aquisições são os insumos para produzir os produtos do projeto (DINSMORE; CAVALIERI, 2003; PMBOK, 2008). Dessa forma, no gerenciamento dos custos deve-se descrever de forma clara que as metas do projeto serão executadas dentro do orçamento previsto, assim como a política de redução dos custos fixos e variáveis que será adotada em todas as fases do projeto.

O Gerenciamento da qualidade de forma adequada assegura que as necessidades que originaram o seu desenvolvimento serão satisfeitas. Um projeto tem qualidade quando é concluído em conformidade aos requisitos, e adequação ao uso e é composto pelos processos: planejar a qualidade, realizar a garantia da qualidade e realizar o controle da qualidade (DINSMORE; CAVALIERI 2003; PMBOK, 2004). O gerenciamento da qualidade deve ser implementado em todas as fases do projeto, por meio da padronização dos processos garantia da qualidade esperada.

O Gerenciamento dos recursos humanos preocupa-se em proporcionar a melhor utilização das pessoas envolvidas no projeto. Ela é composta pelos processos de desenvolver o plano de recursos humanos, mobilizar a equipe de projeto, desenvolver a equipe do projeto e gerenciar a equipe do projeto (DINSMORE; CAVALIERI 2003; PMBOK 2004).

Nesse sentido, recomenda-se planejamento dos recursos humanos com a descrição do perfil dos cargos dentro das necessidades identificadas na execução das tarefas, para a contratação o profissional que enquadre dentro da filosofia organizacional do projeto, estabelecendo uma política de remuneração adequada a realidade do mercado, assim como, mensurar e reconhecer o desempenho das pessoas $\mathrm{e}$ desenvolve-las para o alcance dos objetivos do projeto.

O gerenciamento das comunicações apresenta-se os processos para assegurar a geração, captura distribuição e apresentação das informações do projeto para que sejam feitas de forma adequada e no tempo certo. O gerente de projeto pode gastar parte do seu tempo envolvido com algum tipo de comunicação, seja formal, informal, verbal, escrita. Esse processo é composto pelos processos de identificar as partes interessadas, planejar as comunicações, distribuir as informações, gerenciar as expectativas das partes interessadas e reportar o desempenho (DINSMORE; CAVALIERI, 2003; PMBOK, 2004). Recomenda-se então, a contratação de um profissional da área de comunicação social que terá como competência, divulgar, por meio de releases, matérias, material publicitário e demais instrumentos de comunicação as ações realizadas no projeto, garantindo assim, a publicidade das ações.

O gerenciamento dos riscos descreve os processos para identificação, análise e resposta aos 
riscos do projeto. Ele é composto pelos processos de planejar o gerenciamento dos riscos, identificação os riscos, realização da análise qualitativa dos riscos. Realização da análise quantitativa dos riscos, planejar as respostas aos riscos, monitorar e controlar os riscos (DINSMORE; CAVALIERI, 2003; PMBOK, 2004). No gerenciamento dos riscos, recomenda-se a implantação de um sistema com indicadores de desempenho para a identificação e controle dos riscos e incertezas na execução das tarefas de forma qualitativa e quantitativa, por meio de um plano de contingência para os riscos financeiros, sociais, políticos, durante a vigência do projeto.

$\mathrm{O}$ gerenciamento das aquisições trata-se da aquisição de produtos e serviços fora da organização que desenvolve o projeto. Este gerenciamento é discutido do ponto de vista do comprador na relação com o fornecedor. Ele é composto pelos processos de planejar as aquisições, conduzir as aquisições, administrar as aquisições, encerrar as aquisições (PMBOK, 2018). O gerenciamento de aquisições desenvolve um conjunto de processos visando obter os produtos ou serviços que serão utilizados como insumos na execução do projeto junto aos fornecedores. O gerenciamento de aquisições é uma área de gestão de projetos que interage com as demais.

O último processo trata-se do gerenciamento das partes interessadas, nela correm os processos de identificação dos interesses das pessoas diretamente envolvidas e beneficiadas, e o impacto no sucesso do projeto. Planejamento do gerenciamento das partes interessadas ocorre por meio da implementação de estratégias para quebrar a resistências das pessoas envolvidas de forma direta ou indireta e assim garantir o engajamento no projeto. Gerenciamento do engajamento das partes interessadas, ocorre por meio da implementação de um sistema de comunicação e interação para atender as necessidades do projeto. $\mathrm{O}$
Controle do envolvimento das partes interessadas, ocorrem por meio da implementação de um sistema de monitoramento dos relacionamentos das partes interessadas, com o propósito de ajustar as estratégias para engajar as pessoas envolvidas, eliminando as resistências e aumentando o suporte do projeto (PMBOK, 2018).

Em resumo, a utilização do Guia PMBOK de forma adequada, permite a padronização de todos os processos gerenciais divididos em grupos, que podem ser subdivididos em etapas do projeto. Dito isto, a integração desses processos permite uma visão sistêmica do gestor responsável pelo projeto no tocante ao desempenho das ações. Uma vez que, a escolha da metodologia adequada para aplicação da ferramenta de gestão pertinente a cada processo gerencial, permite a adoção de medidas corretivas no momento do curso das ações para não perder de vista os resultados esperados previstos no escopo do projeto.

Por isso a partir deste ponto, a demonstrar os debates em torno das definições acerca daquilo que se entende como projetos sociais.

\section{PROJETOS SOCIAIS}

O artigo $5^{\circ}$ da Constituição Federal de 1988 estabelece que, todos são iguais perante a lei, sem distinção de qualquer natureza, garantindo-se aos brasileiros e aos estrangeiros residentes no País, a inviolabilidade do direito à vida, à liberdade, à igualdade, à segurança e à propriedade (BRASIL, 1988). Nesse sentido, a carta magna garante a dignidade da pessoa humana como um direito à cidadania plena.

Nesse aspecto, a palavra cidadania tem origem grega e indicava os habitantes da cidade que participavam da vida política da cidade, na qual eram apenas os grandes proprietários de terra e os comerciantes. Então, os escravos, mulheres, crianças e velhos não eram considerados cidadãos, pois, não 
podiam participar da política (LEITE; SANCHEZ, 2017).

Dessa forma, o termo cidadania vem passando por transformações, sendo alvo de muitos debates, na qual não se chega numa decisão sobre o seu significado. Porém, com o passar da evolução da sociedade, cidadania passar a ser o elo jurídico ligando um individuo ao estado, sendo a prática de direitos e deveres perante o estado (VICENTE et al., 2012). Assim sendo, os projetos sociais são ferramentas utilizadas como forma de organizar ações para transformar determinada realidade social por meio do acesso dos cidadãos e cidadãs aos direitos a cidadania plena.

Nesse sentido, entende-se que a cidadania é o estatuto, na qual depende das leis de cada estado, sendo diferente em cada país. O conjunto de três componentes da cidadania traduz pelo que se entende de cidadania ativa, sendo esses componentes: cidadania civil, cidadania política e cidadania social (VICENTE et al., 2012). Nesse aspecto, o acesso a essas cidadanias podem ser democratizadas a partir da criação de instrumentos de acesso denominados de projeto social, implementado por meio da execução de um conjunto de atividades temporárias e específicas destinadas a resolver um problema publico que afeta um segmento específico da sociedade.

Desse modo, os projetos sociais são instrumentos de gestão fundamentais para facilitar o acesso dos cidadãos e cidadãs aos direitos sociais tais como; educação e saúde, então se tratam da cidadania social. Esses direitos são de responsabilidade do poder público, seja da esfera federal, estadual ou municipal para garantir a segurança e qualidade de vida, todavia também deve ser disposto pela sociedade civil (VICENTE et al., 2012). Diante dessas considerações, pode-se afirmar que um projeto é pensado para provocar mudanças, ou seja, trazer uma contribuição real de transformação para uma determinada comunidade impactada por um problema público.

Conforme Maciel (2015), os projetos sociais nascem do desejo de mudar certa realidade, sendo como pontes entre a realidade e o desejo. Os projetos podem também compor a chance de participação e expressão no que é público e coletivo. Isso é possível através das transformações marcantes entre o público e o privado, sendo uma ferramenta de gestão utilizada tanto pelo Estado quanto pela sociedade civil organizada. Esses projetos nascem para dar respostas aos problemas que afetam a sociedade e são responsáveis por alterar a realidade do público alvo beneficiário.

Em resumo, os projetos sociais surgem do desejo de atores públicos ou privados de mudar uma realidade por meio da implementação de ações planejadas, podendo ser executadas pelos entes públicos ou por organizações da sociedade civil, que identifiquem uma problemática de interesse público por meio da realização de um diagnóstico.

\section{Projetos sociais no Brasil}

No Brasil, os projetos sociais surgiram a partir da década de 40, em 17 de fevereiro de 1940, o Presidente Getúlio Vargas, baixa o Decreto-Lei $N^{\circ}$ 2.024, que estabelece as bases da organização da proteção à maternidade, à infância e à adolescência em todo o País. Essa lei determinava a implementação de medidas governamentais voltadas para a proteção da maternidade, à infância e à adolescência (BRASIL, 1940).

De acordo com Tavares (2009), os projetos sociais no Brasil surgiram de fato a partir da década de 50, por meio do empenho da sociedade em solucionar os problemas sociais existentes no país, problemas estes que o governo apresentou dificuldades para resolvê-los. Assim sendo, pode-se deduzir que nesse período prevalecia no Brasil os 
projetos esportivos de cunho sócio-educativo voltados para crianças e adolescentes.

Atualmente, os direitos sociais estão resguardados no artigo $6^{\circ}$ da Constituição Federal de 1988, que estabelece como direitos sociais a educação, a saúde, o trabalho, a moradia, o lazer, a segurança, a previdência social, a proteção à maternidade e à infância, a assistência aos desamparados, na forma desta Constituição (BRASIL,1988).

Em síntese, pode-se observar que os projetos sociais no Brasil se enquadram num horizonte de construção de direitos e afirmação cidadã, consagrados na Constituição Federal de 1988. Sua ênfase é a noção de justiça social, o que somente pode ser alcançado através da participação e do exercício da cidadania (STEPHANOU, 2003).

\section{Projetos Sociais no Tocantins}

No caso do Tocantins, a previsão do estabelecimento de projetos sociais está prevista no artigo 121 da Constituição Estadual que estabelece que o Estado e os municípios implementarão programas de prevenção e atendimentos especializados, incluindo educação física, esporte e lazer às crianças e ao adolescente dependente de entorpecentes e drogas a fins (TOCANTINS,1989). Nesse aspecto, a Constituição do Estado do Tocantins, tratou de resguardar a inclusão social dos tocantinenses que carecem de apoio do poder público, por meio de programas de assistência integral permitindo o acesso gratuito a assistência social e psicológica, esporte, cultura e lazer.

Como consequência, com base nesse dispositivo, em 20 de fevereiro de 1991, o Governador José Wilson Siqueira Campos, sanciona a Lei № 258, que cria a organização dos Pioneiros Mirins no Estado do Tocantins, como um serviço e promoção humana e social dos menores Tocantinenses. A organização tinha como objetivo central a promoção do menor com a melhoria de suas condições físicas, emocionais e intelectuais. A gestão financeira da organização ficou sob a responsabilidade da Fundação Santa Rita de Cássia, que tinha como principal atribuição a criação de unidades nos municípios do Estado (TOCANTINS, 1991).

Posteriormente, em 20 de março de 1992, o Governador Moisés Avelino, através do Decreto $\mathrm{N}^{\circ}$ 5.402, regulamenta a Lei $\mathrm{N}^{\circ} 258$ de 20 de fevereiro de 1991, alterando a denominação de Organização dos Pioneiros Mirins para Programa Pioneiros Mirins, com a finalidade de encaminhar os meninos e meninas carentes nas faixas etárias de 7 a 17 anos, para atividades educativas e integrativas, objetivando agir de forma proativa dos graves desvios sociais, decorrentes da precariedade das condições sociais e econômicas das famílias dos beneficiários por meio de reforço escolar; atividades de arte e educação; atividades desportivas e de lazer; cursos profissionalizantes; palestras informativas e educativas nas áreas de saúde, social, religiosa e civismo (TOCANTINS, 1992).

De fato, em 26 de julho de 1996, o Governador José Wilson Siqueira Campos, sanciona a Lei $\mathrm{N}^{\circ}$ 856, que institui a Bolsa de Complementaridade Escolar, destinada aos Pioneiros Mirins que tenham frequência sistemática na unidade, podendo envolver estágio de iniciação no trabalho, na faixa etária apropriada. Para beneficiar-se da bolsa de complementaridade escolar, o pioneiro mirim deveria estar devidamente matriculado numa instituição de ensino e apresentar frequência mensal, de sua participação escolar, à coordenação do programa (TOCANTINS, 1996).

Efetivamente, em 23 de dezembro de 2009, o Governador Carlos Henrique Amorim, sanciona a Lei No 2.268, que institui a Fundação Pioneiros Mirins, entidade autárquica, vinculada à Secretaria de Educação e Cultura, com autonomia administrativa, 
financeira e patrimonial. Alei estabelece ainda que, a fixação das políticas e diretrizes relacionadas às ações de caráter social do Programa Pioneiros Mirins, fica Secretaria de Trabalho e Desenvolvimento Social (TOCANTINS,2009). A entidade foi criada com o objetivo de reestruturar o antigo Programa Pioneiros Mirins, mas não entrou em operação.

Por certo, em 31 de março de 2011, o Governador Siqueira Campos, sanciona a Lei 2.434, alterou e consolidou as estruturas operacionais e os quadros de provimento em comissão dos órgãos do Poder Executivo, oportunidade em que por meio da alínea "j" do inciso I de seu artigo 10, transformou a Fundação Pioneiros Mirins de Apoio à Infância e à Juventude - PIONEIROS MIRINS, em Instituto Pioneiros Mirins de Apoio à Criança e ao Adolescente, “órgão autônomo" vinculado à Secretaria da Educação (TOCANTINS, 2011).

Similarmente, em $1^{\circ}$ de março de 2012, o Governador Siqueira Campos, sanciona a Lei $\mathrm{N}^{\circ}$ 2.562, que tratou de extinguir por meio de seu artigo $2^{\circ}$, o Instituto Pioneiro Mirins, então vinculado à Secretaria da Educação. A mesma lei estabelece a criação na estrutura da Secretaria do Trabalho e da Assistência Social, o cargo em comissão de Superintendente do Programa Pioneiro Mirins, a quem atribuiu à função de liquidante (TOCANTINS, 2012a).

De maneira idêntica, em 27 de abril de 2012, foi sancionada a Lei Complementar $\mathrm{N}^{\circ} 79$, dispondo sobre a organização básica da Polícia Militar do Estado do Tocantins, instituindo uma assessoria junto à Secretaria do Trabalho e da Assistência Social (SETAS), como órgão de apoio da PMTO, ao qual foi atribuída a tarefa de auxiliar o Comando Geral junto ao Programa Pioneiros Mirins, nos termos do §2o de seu artigo 14, reconhecendo a execução das atividades do referido Programa como pertinentes também à Polícia Militar do Estado do Tocantins, em apoio à
Secretaria do Trabalho e à Assistência Social (TOCANTINS, 2012b).

Assim também, em 4 de julho de 2013, foi aprovada a Lei 2.734 , que estabelece a reorganização da estrutura organizacional do Poder Executivo, ao alterar e consolidar as estruturas operacionais e os quadros de dirigentes e assessores, criando na Secretaria do Trabalho e à Assistência Social, o Departamento do Programa "Pioneiros Mirins (TOCANTINS,2013).

Definitivamente, em 19 de outubro de 2017, o governador Marcelo Miranda, encaminhou para a Assembleia Legislativa a Medida Provisória $\mathrm{N}^{\circ}$ 42/2017, extingue formalmente o Programa Pioneiros Mirins, inativo desde 2014. A justificativa apresentada pelo governo para a extinção do programa, foi que a partir de 2015, quando iniciada a Gestão, não existia cargo de provimento em comissão ou setor administrativo com atribuição relacionada ao Programa. Os problemas sistêmicos verificados no âmbito do Programa culminaram, progressivamente, em sua inativação, porém, as demandas sociais inerentes à infância e à juventude passaram a ser atendidas no âmbito de outras políticas públicas.

Em resumo, o governo enfatiza ainda que ao longo dos tempos outras áreas de atenção sócioeducacional, do desporto, de assistência social e de saúde às crianças e adolescentes se fortaleceram no Tocantins, em especial por meio da ampliação das escolas estaduais de tempo integral, incluindo-se as de gestão militar, bem assim da atuação estatal junto aos Centros de Referência de Assistência Social (CRAS), mantidos em todos os municípios tocantinenses com o propósito de combater as diversas situações de vulnerabilidade social da família, contemplando as diversas faixas etárias de seus membros (TOCANTINS,.,2017).

\section{Projetos Sociais na Região Sudeste do Tocantins}


O Projeto de Inclusão Social, pioneiro no Tocantins, teve início ainda quando o estado pertencia ao norte de Goiás. O projeto pioneiro foi o Instituto de Menores de Dianópolis, atualmente Região Sudeste do Tocantins, fundado em 1953, pelo ex-Deputado por Goiás Hagahus Araújo. $\mathrm{O}$ projeto tinha como finalidade, o internato de meninos nas faixas etárias de 8 a 18 anos, oriundos de vários municípios do norte de Goiás, posteriormente Tocantins, os alunos do instituto participavam de atividades escolares, esporte, cursos profissionalizantes e aulas de músicas. $\mathrm{O}$ projeto era mantido pelo Governo do Estado e com recursos do Orçamento da União destinados por deputados da bancada de Goiás na Câmara Federal (ALENCAR, 2003; AIRES NETO, 2006).

Dessa forma, é importante ressaltar que, o Instituto de Menores de Dianópolis funcionou por 59 anos, teve suas atividades encerradas em dezembro de 2012. Com o encerramento das atividades a estrutura física que funcionava em uma área rural de aproximadamente 600 hectares, foi doada pelo Estado do Tocantins ao Instituto Federal de Educação, Ciência e Tecnologia do Tocantins (IFTO), que passou a funcionar no dia 13 de maio de 2013, com um total de 150 vagas ofertadas nos Cursos: Técnico em Informática e em Agropecuária Subsequentes ao Ensino Médio, distribuídas nos três turnos (RELATÓRIO-IFTO,.,2015).

Em síntese, em Dianópolis, cidade de realização desta pesquisa, atualmente existe em funcionamento o projeto social de iniciação esportiva na modalidade de futebol de campo, Escolinha de Futebol Educando através do Esporte, o público alvo são crianças e adolescentes nas faixas etárias de 07 a 15 anos. Bem como, o projeto JUMP com o propósito de queimar calorias das participantes, o público alvo são pessoas do sexo feminino sem limites de idade, atualmente atende aproximadamente 50 mulheres, também executado pela Secretaria de Esportes e Juventude.

Todavia, é importante destacar que, não foi possível identificar registros de cunho bibliográfico ou documental, que comprove a existência de outros projetos sociais no Município de Dianópolis. No entanto, pode-se pressupor que foram executados outros projetos sociais no município, principalmente a partir da instalação do Estado em $1^{\circ}$ de janeiro de 1989 (SECRETARIA...., 2019).

Em síntese, pode se afirmar que os projetos sociais podem ser uma forma concreta para o exercício da cidadania por meio do acesso de pessoas às políticas públicas pensadas para resolver um problema público que afeta diretamente um segmento específico de uma população. A efetiva implementação de uma política pública devidamente sistematizada e delimitada em um projeto social, assegura os direitos constitucionais aos cidadãos e cidadãs beneficiários. Posto isso, na seção seguinte será apresentada a metodologia deste trabalho.

\section{MATERIAIS E MÉTODOS}

Este trabalho, de caráter descritivo e exploratório, está inscrito no paradigma interpretativo. Dessa forma, ontologicamente entende-se que a sociedade é uma construção dos seus membros e a realidade social é formada por ocasião de interações realizadas pelos atores envolvidos, uma vez que eles são capazes de interpretação e de ações significativas (ALENCAR, 2007). Dessa forma, a metodologia escolhida é essencialmente qualitativa, realizada por meio de pesquisa documental, bibliográfica e estudo de caso por meio da aplicação de questionário. Inicialmente foram realizadas visitas à Secretaria de Esportes e Juventude, de forma, identificar os responsáveis pela execução dos projetos sociais e assim formalizar por meio de ofícios a autorização para a execução da pesquisa. Cabe destacar que o 
período de aplicação do questionário ocorreu entre 22 de agosto e 20 de setembro de 2019, na Prefeitura de Dianópolis Tocantins. O órgão, o número de entrevistados e a natureza dos questionamentos serão expostos a seguir.

Foi aplicado um questionário padrão estruturado com dez questões abertas, ao Secretário de Esportes e Juventude. O questionário continha solicitações de informações acerca do modelo de gerenciamento de Projetos Sociais estabelecidos pela Prefeitura de Dianópolis, e executados pela Secretária de Esportes e Juventude. A escolha desse respondente deu-se pelo papel privilegiado na condução desse órgão que tem como finalidade, a execução de projetos sociais, de forma que os resultados desta pesquisa possam apresentar um bom panorama dos resultados desse conjunto de ações. Somadas a essas ações, foram realizadas consultas a documentos de diversas tipologias, entre os meses de agosto e outubro de 2019, agrupados da seguinte maneira: 1) Projeto impresso da escolinha de iniciação esportiva na modalidade de futebol, denominado de Educando através do Esporte; 2) Projeto impresso que objetiva atender mulheres que queiram queimar calorias, denominado de JUMP.

\section{RESULTADOS E DISCUSSÃO}

Diante das questões apresentadas nos instrumentos de coletas de dados, procurou-se identificar nas Secretarias de Esportes e Juventude de Dianópolis, as seguintes variáveis:a) o modelo de gerenciamento de projetos; b) os tipos de projetos; c) as estratégias adotadas na elaboração e gerenciamento de projeto; d) o perfil do gestor responsável pela gestão de projetos e o público beneficiário. Identificou-se que, atualmente existem em funcionamento os projetos sociais: Educando através do Esporte e o Projeto JUMP, ambos executados pela Secretaria de Esportes e Juventude.
Uma vez que, o Projeto Educando através do Esporte, trata-se de uma escolinha de futebol voltada para a iniciação esportiva de crianças, pertencentes aos sexos masculinos e femininos, nas faixas etárias de 07 a 15 anos. O projeto iniciou as atividades em janeiro de 2018, e atualmente atende 100 crianças. Na gestão desse projeto, trabalham quatro pessoas, sendo o gestor, com formação em eletrotécnico, e dois instrutores de futebol com o ensino médio completo, visto que, um deles atuou como jogador de futebol profissional e uma professora formada em educação física. O projeto JUMP, tem como público alvo, mulheres sem limites de idade que queiram queimar calorias por meio da prática de atividades físicas orientadas. A gestão desse projeto fica a cargo de uma professora de educação física. Neste projeto, atualmente são atendidas aproximadamente 50 mulheres.

Diante das informações expostas, a seguir serão apresentados os resultados da entrevista com o 91 Secretário de Esportes e Juventude. O mesmo tem a profissão de eletrotécnico e está no cargo desde 2017.

Sobre quais os tipos de projetos que são desenvolvidos pela secretaria, o secretário assim descreveu:

Os projetos que a secretária desenvolve no momento são: O Educando através do Esporte, conhecida como escolinha de futebol; projeto AABB Comunidade; Projeto JUMP; projetos de futebol na zona rural nas seguintes comunidades: Quilombola Lajeado; Novo Plano; Boa Sorte; Tucuzinho e na Escola Vargão, mas o projeto não possui um nome específico. Além disso, o Projeto de corrida de rua que vai acontecer no aniversário de Dianópolis, também somos apoiadores do projeto ciclismo. Mas a escolinha de futebol é a nossa principal prioridade (SECRETARIA...,2019). 
Sobre quais as medidas que são adotadas antes da elaboração dos projetos sociais que estão sendo executado pela secretaria, o secretário assim opinou:

[...] Para fazer a elaboração de um projeto assim como o caso da escolinha de futebol identificamos a real necessidade da cidade, através de alguns critérios tais como: setores mais carentes, as escolas mais afastadas que estão nos setores pobres. O objetivo é ocupar tempo dos meninos para que eles sigam outros caminhos. Além do bem-estar deles a gente visa também o futuro dessa criança (SECRETARIA...,2019).

Sobre como é feito o planejamento e gestão dos projetos sociais da secretaria, o secretário assim manifestou:

Tem os projetos já citados, mas a escolinha de futebol é o que funciona de forma estruturada e organizada. O Projeto da escolinha de futebol, a atual gestão já recebeu pronto, mas tivemos que mudar ele todo. Ele estava há vários anos sem funcionar, na verdade, resgatamos e tivemos muita dificuldade no primeiro ano, porque foi necessário correr atrás de material de consumo do projeto por meio de licitações. A prefeitura por meio da Secretaria de Esportes e Juventude, está gerenciando-o desde 2017, e queremos continuar até o final deste mandato, e deixar bem organizado para o próximo gestor. [...] $\mathrm{Na}$ realidade, existem outros projetos, mas enfrenta muita dificuldade financeira, porque a prefeitura estar passando por muita escassez de recursos, então, nos escolhemos um projeto e não que é o melhor e o que a gente achou que valoriza mais a população [...] Não é possível fazer um planejamento da gestão dos recursos financeiros, pois, não temos um valor financeiro certo para a gente planejar e executar os projetos [...] (SECRETARIA...,2019).

Sobre se o secretário atuou anteriormente na gestão dos projetos, o mesmo afirmou que: [...] não trabalhou na gestão de projetos antes de assumir o cargo de secretário, sendo a primeira experiência [...] (SECRETARIA...,2019).

No tocante ao perfil do público beneficiário no projeto, o secretário assim manifestou:

Focamos nas crianças carentes matriculadas nas escolas mais afastadas do centro da cidade, em áreas de risco, por mais que priorizamos essas escolas, não deixamos de atender o centro. São crianças de 07 a 15 anos. No início foi aberto para meninos e meninas, mas o número feminino não foi o suficiente (SECRETARIA...,2019).

Sobre os critérios que são adotados para as crianças participarem do projeto, o secretário declarou:

A criança precisa ter notas boas nas escolas e bom comportamento. Fizemos uma reunião e foi decidido que os pais são os responsáveis por trazer o boletim a cada semestre e por isso, que teve uma melhora no rendimento escolar dessas crianças. (SECRETARIA...,2019).

Com relação às fontes de recursos para aplicarem na gestão dos projetos, o secretário afirmou que:

A secretaria dispõe de orçamento para executar os projetos, tudo depende da prefeitura, do prefeito. Se a secretaria decidir executar uma ação com as crianças matriculadas no projeto, tenho que falar com o prefeito e dizer que não temos recursos. Tivemos um bloqueio do Governo Federal na liberação de recursos para os projetos. Em 2013, houve um programa federal que foi destinado à secretaria de esportes, mas gestão da época não prestou contas desse dinheiro, por esse motivo, estamos impedidos de fazer convênios com governo federal, então os projetos ficaram todos dependendo das receitas do município. O único projeto que a está ao alcance da prefeitura é a escolinha, que na realidade não é um projeto caro, só precisa do material esportivo, do 
uniforme e dos professores (SECRETARIA...,2019).

Com relação se os recursos são suficientes para atender os objetivos do projeto, o secretário assim opinou:

Deixamos de fazer uma ação por falta de dinheiro e em alguns casos, tiramos recursos do próprio bolso. Os novos alunos que estão aderindo ao projeto têm que comprar o próprio uniforme. Fizemos uma nova licitação para renovar os uniformes, mas até hoje não conseguimos renovar e estão com os mesmos uniformes desde 2018 (SECRETARIA...,2019).

Sobre os critérios adotados para contratar as pessoas que trabalham na gestão de projetos, o secretário assim afirmou:

Acredito que não tem critério, mas hoje a gestão tem um funcionário contratado só para mexer com projeto em todas as secretarias, em todas as áreas, só que tipo assim, ele para nós não estar servindo para nada porque não podemos fazer esses convênios. Os professores da escolinha de futebol, por exemplo; o critério é ter sido jogador de futebol e possuir no mínimo o ensino médio, já o coordenador é formado em educação física (SECRETARIA...,2019).

Sobre se a Secretaria promove capacitação específica para gestão de projeto, o secretário assim opinou:

[...] A secretaria não dispõe de cursos de capacitação específica para atender as pessoas que trabalham na gestão de projeto [...] (SECRETARIA...,2019).

Diante das informações expostas, a seguir será apresentada a análise dos resultados da pesquisa, a luz da opinião do entrevistado, assim como da interpretação das informações contidas nos projetos impressos identificados nos arquivos da Secretaria de Esportes e Juventude, tendo como parâmetro os processos de gestão estabelecidos pelo Guia PMBOK, pode-se inferir que, o Projeto Educando através do Esporte (escolinha de futebol) é prioritário, porém, não possui um planejamento operacional que permite o gerenciamento de forma sistemática e voltado para a realidade do município, permitindo possíveis falhas durante a execução.

Uma vez que, a falta de dotação orçamentária e autonomia financeira da secretaria responsável pela execução do projeto, a não reposição dos materiais de consumo de forma adequada, a não capacitação dos funcionários, a ausência de uma equipe técnica capacitada para captação de recursos, assim como, a formação profissional do secretário não está relacionada à gestão de projetos sociais, contribui para a ineficiente dos processos internos, tornando insuficiente para atender a demanda, principalmente a inclusão de meninas no projeto. Conforme as falas do secretário entrevistado, houve avanços no desenvolvimento cognitivo dos beneficiários, ou seja, as crianças participantes, evoluíram no quesito disciplina e melhoria no desempenho escolar, mas tudo isso, pode não ser o suficiente para o alcance de um impacto social.

Por outro lado, o Projeto JUMP, conforme mencionado nas falas do secretário entrevistado, não funciona de forma planejada, inviabilizando assim, a real identificação por parte dos pesquisadores, as devidas responsabilidades pelas atividades do projeto e atribuições das pessoas envolvidas. Dessa forma, pode-se deduzir que, a secretaria responsável pela execução desse projeto, pela evidente escassez de recursos materiais, humanos e financeiros, não monitora os processos de gestão do mesmo, ficando vulnerável a alteração do escopo, tendo como consequências, o não alcance dos resultados esperados.

Inegavelmente, avalia-se que, as estratégias gerenciais adotadas no Projeto Educando através do Esporte e no Projeto JUMP, não atende aos pré- 
requisitos estabelecidos no Guia PMBOK, que propõe a divisão dos projetos em cinco grupos de processos: iniciação; planejamento; execução e encerramento. Inviabilizando a organização desses processos aos elementos de gerenciamento de projetos tais como: gerenciamento da integração; gerenciamento do escopo; gerenciamento do tempo; gerenciamento dos custos; gerenciamento da qualidade; gerenciamento dos recursos humanos; gerenciamento das comunicações; gerenciamento dos riscos; gerenciamento das aquisições; gerenciamento das partes interessadas.

Em razão disso, a não a aplicação dos princípios de gerenciamento de projetos de forma padronizada conforme recomenda o guia PMBOK, poderá aumentar drasticamente as chances de não atender da melhor forma às necessidades $\mathrm{e}$ expectativas das crianças e mulheres, público alvo, ou seja, os beneficiários dos projetos que estão sendo executados pela Prefeitura de Dianópolis, através da Secretaria de Esportes e Juventude.

\section{CONCLUSÃO}

Concluindo o trabalho, retoma-se o objetivo, que foi o de analisar o modelo de gerenciamento de Projetos Sociais estabelecidos pela Prefeitura de Dianópolis/TO, executados pela Secretaria de Esportes e Juventude no período de $1^{\mathrm{o}}$ de janeiro de 2017 a 20 de setembro de 2019. Foram identificados e selecionados dois projetos sociais: $\mathrm{O}$ Projeto Educando através do Esporte e o Projeto JUMP. O primeiro lançado em 2017, e o segundo no ano posterior, ambos mostrando que a Prefeitura de Dianópolis, aposta na implementação de projetos como possibilidade do desenvolvimento humano e social das crianças e mulheres do município. Importante ressaltar que, a resolução de problemas públicos por meio de projetos sociais, pode ser considerada como binômio de impactos sociais nas décadas passadas, antes da invasão das inovações tecnológicas e das redes sociais. Dessa forma, o município optou por modelos de gerenciamento de projetos que não funcionam no contexto atual. A secretaria estudada não adota um modelo de gerenciamento de projeto padronizado como elemento norteador do planejamento e da gestão.

Na opinião dos autores deste trabalho, um dos motivos da não utilização do PMBK, pela Secretaria de Esportes e juventude, como um instrumento norteador do planejamento e da gestão dos projetos sociais Educando através do Esporte e Projeto JUMP, que possibilita a padronização dos processos, estabelece diretrizes claras de gerenciamento e socialização da informação de maneira adequada, garantindo assim maior confiabilidade e qualidade dos serviços fins, não está relacionada tão - somente a escassez de recursos, mas também, a baixa qualificação técnica, tanto do principal gestor da pasta, quanto dos funcionários que atuam na operacionalização das atividades desses projetos.

Sugere-se então que, o próximo Prefeito de Dianopolis, constitua uma equipe técnica interdisciplinar capacitada para atuar na elaboração de projetos em conformidade com os padrões internacionais, captação de recursos junto aos organismos de fomento, seja estadual, federal ou internacional, gerenciar projetos com a aplicação das metodologias e tecnologias que melhor se adaptarem as contingências ambientais locais.

\section{REFERÊNCIAS}

AIRES NETO. Abílio Wolney. Memórias de João Rodrigues Leal. Goiânia, edição do autor, 2006, $421 \mathrm{p}$.

ALENCAR, Iara Araújo. Hagahús Araújo: uma lição de cidadania. Organização, pesquisa e texto final Iara Araújo Alencar. Brasília: Ideal, 2003.

ALENCAR, E. Pesquisa em turismo. Lavras: Ufla; Faepe, 2007. 174p. 
BRASIL. Constituição de (1988). Constituição da república Federativo do Brasil. Brasília, DF, Senado Federal, Secretaria especial de editoração e publicações subsecretaria de edições técnicas abril / 2016, p. 61.

. Decreto-Lei $\mathrm{N}^{\circ} 2.024$, de 17 de fevereiro de 1940. Fixa as bases da organização da proteção à maternidade, à infância e à adolescência em todo o País. Disponível em: https://www2.camara.leg.br. Acesso em 11 de agp./2019.

DINSMORE, C. e CAVALIERI, A. Como se Tornar um Profissional em Gerenciamento de Projetos: Livro-Base de "Preparação para Certificação PMP Project Management Professional". Rio de Janeiro: QualityMark, 2003.

\section{GAUDEOSO, Erika Costa da Silva. Implementação} de Projetos Sociais. Revista Pensamento \& Realidade, v. 29, n. 2, 2014, p. 105-109. Disponível em https://ken.pucsp.br/pensamentorealidade. Acesso em 25de fev./2020.

KEELING, Ralph. Gestão de projetos: uma abordagem global. Tradução Cid Knipel Moreira; revisão técnica Orlando Cattini Jr. São Paulo: Saraiva, 2002.

LACOMBE, F. J. M. Dicionário de administração. São Paulo: Saraiva 2004. 358p.

LEITE, David de Medeiros; SANCHEZ, Zulimar Sanches (orgs.). A participação cidadã na administração pública e a evolução do direito administrativo. Mossoró - RN: EDUERN, 2017.

LEWIS, James P. Como gerenciar projetos com eficácia. COUTO, Gilberto de Araújo Brandão. (Tradução). Rio de Janeiro, Campos, 2000. 105 p.

MAXIMINIANO, Antonio Cesar Amaru. Teoria geral da administração: da revolução urbana à revolução. São Paulo: Atlas, 2012.

MENEZES, Luís César de Moura. Gestão de projetos.

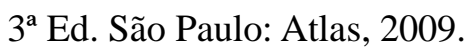

MACIEL, Walery Luci da Silva. Projetos sociais: livro didático. Designer instrucional Marina Melhado Gomes da Silva. Palhoça: UnisulVirtual, 2015.
OLIVEIRA, André Bernardo de; CHIARI, René. Gerenciamento de projetos baseado no PMBOK $5^{\text {a }}$ edição. $2^{\mathrm{a}}$ Ed. São Paulo: Communit, 2015.

PRIETO, Marcos; MÉXAS. Mirian Picinini. Eficiência no Gerenciamento de Projetos: Uma revisão bibliográfica. XII Congresso Nacional de Excelência Em Gestão-III INOVARSEResponsabilidade Social Aplicada. Universidade Federal Fluminense, Rio de Janeiro, 29 e 30 de setembro de 2016. Disponível em http://www.inovarse.org/sites/default/files. Acesso em 24 de fev./2020.

PMI. Um Guia do Conhecimento em Gerenciamento de Projetos. Guia PMBOK®. Quarta Edição - EUA: Project Management Institute, 2008.

PMBOK. Um Guia do Conhecimento em Gerenciamento de Projetos. Guia PMBOK®. Sexta Edição- EUA: Project Management Institute, 2018.

Guia. Um guia do conhecimento em gerenciamento de projetos. [texto e tradução] Project Management Institute. $5^{\text {a }}$ Ed. São Paulo: Saraiva, 2014.

Guia. Um guia do conhecimento em gerenciamento de projetos. [texto e tradução] Project Management Institute. $4^{\text {a }}$ Ed. São Paulo: Saraiva, 2008.

Guia. Um guia do conjunto de conhecimento em gerenciamento de projetos. [texto e tradução] Project Management Institute. $3^{\mathrm{a}}$ Ed. São Paulo: Saraiva, 2004.

RELATÓRIO-IFTO (2015). Instituto Federal de Educação, Ciência e Tecnologia do Tocantins (IFTO). Relatório de gestão - exercício 2015. Disponível em: http://www.ifto.edu.br/ relatórios de gestão. Acesso em 10 de jun./2018.

SECRETARIA MUNICIPAL DE ESPORTES E JUVENTUDE. Projetos impressos, Educando Através do Esporte e JUMP, Dianópolis, 2019.

Secretário Municipal de Esportes e Juventu pesquisa. 2019. 
SHEPPARD, Michael. Social work and social exclusion: the idea of practice. Aldershot: Ashgate, 2006.

TAVARES, Marialva. Análise de projetos sociais: caminho para melhorar o ensino. São Paulo, 2009.

TOCANTINS. Constituição (1989). Constituição do Estado do Tocantins. Palmas, TO, Assembleia Legislativa, $11^{\mathrm{a}}$ edição atualizada e revisada,2012.

TOCANTINS. Lei 258 de 20 de fevereiro de 1991. Cria a organização dos Pioneiros Mirins no Estado do Tocantins. Disponível em: https://www. diariooficial.to.gov.br/busca. Acesso em 10 de set./2019.

Decreto $\mathrm{N}^{\circ} 5402$ de 20 de março de 1992. Regulamenta a Lei 258 de 20 de fevereiro de 1991, que Cria a organização dos Pioneiros Mirins no Estado do Tocantins e dá outras providências. Disponível em: https://www. diariooficial.to.gov.br/busca. Acesso em 10 de set./2019.

Lei 856 de 26 de julho de 1996. Institui a Bolsa de Complementaridade Escolar, destinada aos Pioneiros Mirins, e dá outras providências. Disponível em: https://www. diariooficial.to.gov.br/busca. Acesso em 10 de set./2019.

. Lei 2.268 de 23 de dezembro de 2009. Institui a Fundação Pioneira Mirins, reestrutura o Programa Pioneiros Mirins e adota outras providências. Disponível em: https://www. diariooficial.to.gov.br/busca. Acesso em 10 de set./2018.

Lei 2.434 de 31 de março de 2011. Altera e consolida as estruturas operacionais e os quadros de provimento em comissão dos órgãos do Poder Executivo, e adota outras providências. Disponível em: $\quad$ https://www. diariooficial.to.gov.br/busca. Acesso em 10 de set./2019.

Lei 2.562 de $1^{\circ}$ de março de 2012.

Modifica, na forma que especifica a estrutura operacional da Secretaria do Trabalho e da Assistência Social, e adota outras providências. Disponível em: http://www.al.to.leg.br/Legislação estadual. Acesso em 22 de set./2019.
Lei complementar $\mathrm{N}^{\circ} 79$, de 27 de abril de 2012. Dispõe sobre a organização básica da Polícia Militar do Estado do Tocantins, e adota outras providências. Disponível em: http://www.al.to.leg.br/Legislação estadual. Acesso em 22 de ago./2018.

Lei $\mathrm{N}^{\mathrm{o}}$ 2.734, de 4 de julho de 2013. Reorganiza a estrutura organizacional do Poder Executivo, altera e consolida as estruturas operacionais e os quadros de dirigentes e assessores, e adota outras providências. Disponível em: https://www. diariooficial.to.gov.br/busca. Acesso em 30 de set./2019.

Medida provisória No 42/2017 de 19 de outubro de 2017. Extingue formalmente o Programa Pioneiros Mirins, e adota outras providências. Disponível em: https://www. diariooficial.to.gov.br/busca. Acesso em 30 de set./2019.

VARGAS, Ricardo Viana. Gerenciamento de projetos: estabelecendo diferenciais competitivos. Prefácio de Reeve Harold R. $6^{a}$ Ed. atual. Rio de janeiro: Brasport, 2005.

Ricardo Viana. Gerenciamento de projetos: 96 estabelecendo diferenciais competitivos. $9^{\text {a }}$ Ed. Rio de Janeiro: Brasport, 2018.

VICENTE, Henrique Testa et at. Manual do aluno cidadania e desenvolvimento social. Ministério da Educação de Timor-Leste, 2012. Disponível em: https://issuu.com/universidade-deaveiro/docs/cidadaniads_manualdoaluno_fogra 39. Acesso em: 08 jun. 2019. 